\title{
ULTRASONICALLY ASSISTED SUBSTITUTION AND OXIDATION REACTIONS WITH CAMPHOR
}

\author{
N. Rajitha, K. C. Rajanna*, B. Yadagiri and J. Ramchander \\ Department of Chemistry, Osmania University, Hyderabad-500 007, T. S. (India) \\ *E-mail: kcrajannaou@yahoo.com; kcrchem@gmail.com
}

\begin{abstract}
Substitution (bromination, thiocyanation, and nitration) reactions of camphor (CAMP) were carried out using a variety of oxidizing catalysts such as N-Bromosuccinimide (NBS), N-Bromophthalimide (NBP), N-Bromo acetamide (NBA), trichloroisocyanuric acid (TCICA), ceric ammonium nitrate (CAN), and ammonium metavanadate (AMV) in presence suitable salt as additive. Bromination is conducted with the reagent in presence of $\mathrm{KBr}$, while thiocyanation is done in presence of $\mathrm{NH}_{4} \mathrm{SCN}$ under acid free conditions. However, nitration is carried out in presence of $\mathrm{NaNO}_{2}$ and $\mathrm{KHSO}_{4}$. Noteworthy rate accelerations are recorded in ultrasonically assisted reactions, which were attributed to cavitation effects. On the other hand, the sluggish CAN oxidation of camphor underwent substantial rate acceleration in presence of PEGs and micelles. Present protocols have depicted several greenery features such as simple work-up, fast reaction times, high product yield, eco-friendly and readily available additives as catalysts.

Keywords: bromination, thiocyanation, nitration, oxidation, camphor, sonication, rate acceleration.
\end{abstract}

(C) RASĀYAN. All rights reserved

\section{INTRODUCTION}

Camphor is a bicyclic terpenoid ketone, which is well-known for its uses in medicine and as a plasticizer for nitrocellulose. For several years, camphor was extracted mainly from the Formosan camphor tree. It has been used for hundreds of years as a rubefacient, mild analgesic, lip-balm, chilblain ointment, coldsore ointment and in liniments against rheumatic pain, fibrosis and muscle stiffness. Natural production of camphor has been largely replaced by the synthesis of a race mate from pinene, which is obtained from turpentine oil. Natural camphor is a dextrorotatory ketone ${ }^{1-4}$ with a specific rotation of $[\alpha] \mathrm{D}+42^{\circ}$.
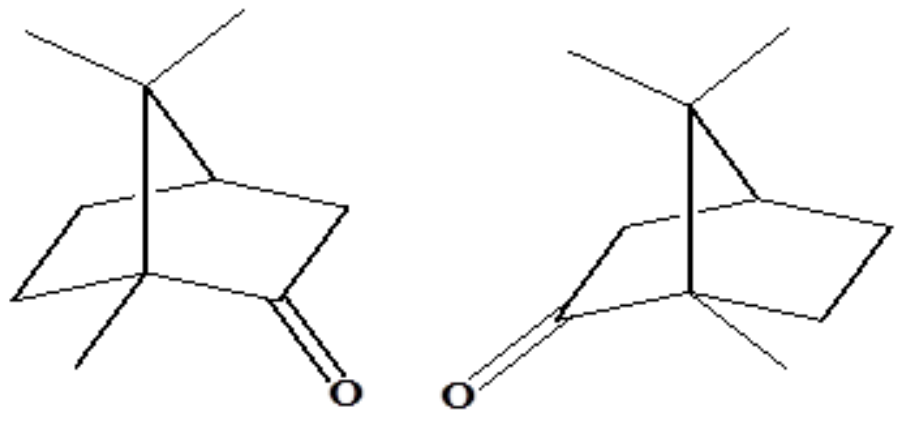

Fig.-1: (R) -(left) and (S)-Camphor

The bromination of camphor has attracted considerable attention, with several of the derived products finding ingenious application as chiral synthons for natural products. (+)-Camphor can be converted into (-)-camphor quinone, and the reaction of this compound with moist bromine was reported by Simonsen et

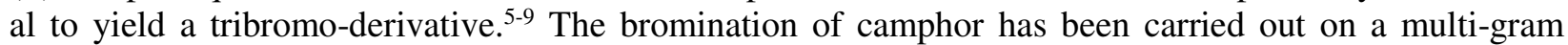
scale by a mixture of $\mathrm{KBr}$ and $\mathrm{KBrO}_{3}$ in the presence of an acid or with $\mathrm{HBr} / \mathrm{NaBr}-\mathrm{H}^{+}$and $\mathrm{H}_{2} \mathrm{O}_{2} / \mathrm{Oxone}$ as the oxidant. The 3-bromocamphor is then efficiently converted to camphor quinone by an improved 
oxidation protocol using DMSO and sodium carbonate of tetrabutylammonium iodide. ${ }^{9}$ Chakrabarty and others developed a simple method of preparation of mechanically and optically interesting nano-diamond films with conventional non-activated CVD process by using camphor (with 75 vol.\% hydrogen) as the precursor material. ${ }^{10,11}$ Kumar and Ando accomplished the synthesis of high-purity carbon nanotubes (CNTs) by chemical vapor deposition of camphor, an environment-friendly hydrocarbon. ${ }^{12}$ Camphorbased CNT synthesis technique is recognized as a fairly good in consonance with green chemistry principles, summarized by Paul Anastas and John Warner. ${ }^{13}$ These principles suggest focusing attention on designing eco-friendly reactions using environmentally safe, economically cheap reagents besides the use of safer solvents, which will prevent environmental pollutions. Recent reviews and publications in the field of Poly ethylene glycol (PEG) mediated organic synthesis revealed that organic reactions performed under these conditions are not only simple but also satisfy both economic and environmental demands by replacing the toxic solvents. ${ }^{14-16}$ The concept of Green Chemistry has emerged as an important area of chemistry and has achieved outstanding progress towards the development of green reaction processes ${ }^{13}$. A survey of the literature reveals that Micelles act as a kind of micro reactors and enhance the rate and selectivity of a variety of chemical and biochemical reactions. ${ }^{17,18}$ A close parallelism between enzymatic reactions and micellar reactions has attracted the attention of several synthetic organic chemists and biochemists. For the past several years, our group has focused its attention on designing synthetic protocols using a variety of eco-friendly materials such as micelle-forming surfactants and unconventional energy sources. ${ }^{19,20}$ Dramatic rate accelerations followed by an increase in the product yield were observed in all these reactions. Encouraged by the striking features and applications of PEGs, micelles, and ultrasound in chemical processes and organic synthesis, ${ }^{17-21}$ coupled with zeal to employ atom economy eco-friendly reagents, the authors have taken up the present study. The proposed work is taken up under conventional and ultrasonically assisted conditions.

\section{Materials and Methods}

\section{EXPERIMENTAL}

All chemicals used were of analytical grade. Doubly distilled water (distilled over alkaline $\mathrm{KMnO}_{4}$ and acid dichromate in an all-glass apparatus) was used whenever required. Acetonitrile and other solvents were HPLC grade and used as such throughout the work. Camphor (CAMP) was procured from Aldrich. N-Bromosuccinimide (NBS), N-Bromophthalimide (NBP), N-Bromo acetamide (NBA), trichloroisocyanuric acid (TCICA), ceric ammonium nitrate (CAN), ammonium metavanadate (AMV), sodium nitrite $\left(\mathrm{NaNO}_{2}\right)$, potassium bromide $(\mathrm{KBr})$, ammonium thiocyanate $\left(\mathrm{NH}_{4} \mathrm{SCN}\right)$, polyethylene glycols (PEGs- PEG -200, PEG -300, PEG -400 and PEG - 600), triton-X 100(TX-100), sodium dodecyl sulfate (SDS), and cetyl trimethyl ammonium bromide (CTAB) were purchased from Avra or SD-fine chemicals (India).

\section{General procedure for substitution reactions}

The reaction mixture containing camphor, co-catalyst $\left(10.0 \mathrm{mmol} \mathrm{KBr}\right.$ for bromination, $\mathrm{NH}_{4} \mathrm{SCN}$ for thiocyanation and $\mathrm{NaNO}_{2} / 0.1 \mathrm{~mol} \mathrm{KHSO}_{4}$ for nitration), catalytic amounts of reagent $(0.4-0.5 \mathrm{~mol}$ percentage), and solvent (acetonitrile, $25 \mathrm{~mL}$ ) were taken in a dried round bottom flask and stirred well till the completion of the reaction. After complete conversion as indicated by TLC, the reaction mixture was quenched with water, treated with a dilute $\mathrm{NaHCO}_{3}$ solution, followed by the addition of ethyl acetate. The organic layer was separated, dried over $\mathrm{Na}_{2} \mathrm{SO}_{4}$ and concentrated under vacuum, purified by column chromatography using hexane: ethyl acetate as eluent to get pure product.

\section{Typical experimental procedure for oxidation of camphor}

A neat mixture of camphor $(1.0 \mathrm{mmol})$ dissolved in acetonitrile and CAN reagent $(1.2 \mathrm{mmol})$ were placed in a 50ml R.B. flask and refluxed till the reaction is completed as ascertained by TLC. After completion of the reaction, the contents were extracted with dichloromethane $(2-25 \mathrm{ml})$ and washed with water (40 $\mathrm{ml}$ ). The reactions were, however, too sluggish even at reflux temperatures. The dichloromethane layer was separated and dried over MgSO4. After evaporation of the solvent, the residue was purified by flash 
column chromatography $\left(\mathrm{SiO}_{2}\right.$, ethyl acetate-hexane 1:2) to afford the end product. The main product of oxidation was characterized as uric acid derivative from IR, NMR and Mass spectroscopic studies.

\section{Typical experimental procedure for PEG / Micelle-mediated oxidation of camphor}

A neat mixture of camphor $(1.0 \mathrm{mmol})$ dissolved in acetonitrile, PEG / micelle forming surfactant and reagent $(1.2 \mathrm{mmol})$ were placed in a $50 \mathrm{ml}$ R.B. flask and refluxed till the reaction is completed as ascertained by TLC. The reactions times significantly decreased in presence of PEG/ micelles. After completion of the reaction, the contents were treated according to the above procedure to a pure product of oxidation, which was characterized as camphoric acid $\left(\mathrm{C}_{8} \mathrm{H}_{14}(\mathrm{COOH})_{2}\right)$. Camphoric acid is saturated dicarboxylic acid with the same number of carbon atoms as camphor, it suggests that keto group is present in one of ring and ring contain keto group is opened in the formation of camphoric acid. It is a colorless, odorless, a crystalline powder with melting-point $\left(180^{\circ}\right.$ to $\left.186^{\circ}\right)$. It gave a yellowish-brown precipitate with ferric chloride and a light blue precipitate with copper sulphate. It could be easily titrated with a normal solution of potassium hydroxide.

\section{Ultrasonically assisted substitution reactions}

Procedure for substitution reaction is largely similar to a conventional procedure. The reaction mixture containing necessary ingredients was placed in a sonicator bath and irradiated with ultrasound till the completion of the reaction. The progress of the reaction was monitored by TLC. Work-up procedure to obtain the products is almost similar to the one discussed in earlier section.

\section{Spectral Information}

Endo-3-bromo-D-camphor: ${ }^{1} \mathrm{H}$ NMR $\left(\mathrm{DMSO}_{6} \mathrm{~d}_{6}\right) \delta=2.31(\mathrm{~m}, 2 \mathrm{H}), 2.32$ (t, 2H), 2.08 (brs, 1H), 1.97 (m, 2H), 1.80 (brs, 1H), $1.42(\mathrm{~m}, 1 \mathrm{H}), 0.94(\mathrm{~S}, 1 \mathrm{H})$; Mass $\mathrm{m} / \mathrm{z} 231.02$ [M+H]; IR Spectra (KBr): 2959.70750.39

Endo-3-thiocyanato-D-camphor: ${ }^{1} \mathrm{H}$ NMR (DMSO-d $\left.\mathrm{d}_{6}\right) \delta=15.9(\mathrm{~s}, 2 \mathrm{H}), 10.3(\mathrm{~d}, 2 \mathrm{H}), 8.6(\mathrm{scn}, 1 \mathrm{H}), 5.9$ (m, 2H), 2.6 (scn, 2H), 1.0 (s, 1H) ; Mass m/z 209 [M+H];IR Spectra (KBr): 3384.89-1678.44

Endo-3-nitro-D-camphor: ${ }^{1} \mathrm{H}$ NMR (DMSO-d $\left.{ }_{6}\right) \delta=7.26(\mathrm{~S}, 2 \mathrm{H}), 2.37(\mathrm{~m}, 2 \mathrm{H}), 2.30(\mathrm{~m}, 1 \mathrm{H}), 1.94(\mathrm{~m}$, 3H), 1.92 (t, 2H); Mass $m / z 209$ [M+H]; IR Spectra (KBr): 3384.89-1678.44

\section{Electrophilic substitution (ES) reactions of Camphor}

\section{RESULTS AND DISCUSSION}

Electrophilic substitution (ES) reactions are important tools in synthetic strategies, which allow the introduction of different functional groups onto an aromatic or non-aromatic ring system. The overall reaction involves the substitution of hydrogen (or sometimes multiple $\mathrm{H}$ ) on the ring system by an electrophile, designated $\mathrm{E}^{+}$. Over the years, several reviews and reports appeared in the literature on electrophilic aromatic substitution (EAS) reactions under conventional and non-conventional conditions. $^{21-30}$

The direct halogenation of aromatic rings employs halogens in the $\mathrm{X}_{2}$ form and generates $\mathrm{HX}$, which are very toxic, corrosive, and polluting agents. In this context molecular bromine has been the most commonly used reagent, which generates toxic and corrosive $\mathrm{HBr}$ as a side product ${ }^{26}$. To minimize the toxic and hazardous effects arising from molecular bromine, "Bromate-bromide (brominating) mixture" along with mineral acid has been used a brominating agent in place of molecular bromine. In this method also excess unused acid and bromination mixture goes into the laboratory/industrial drains. Some other interesting methodologies for bromination of aromatic rings also involve in situ generation of $\mathrm{Br}^{+}$by oxidation of a bromide ion by nitric $\operatorname{acid}^{28}$, hydrogen peroxide ${ }^{29}$, and Oxone ${ }^{30}$. Consequently, considerable efforts have been put over the years to devise newer reagents that can minimize these drawbacks. For this purpose, a large number of $N$-halo reagents $(>\mathrm{N}-\mathrm{X}$, Where $\mathrm{X}=\mathrm{Cl}, \mathrm{Br}$, I etc.) have been extensively developed for use in organic synthesis, which includes $N$-haloamines, $N$-haloamides, $N$ - 
RASĀYAN $J$. Chem.

Vol. 10 | No. 1 | 206 -217 | January - March | 2017

haloimides, $\mathrm{N}$-haloureas, $\mathrm{N}$-halosaccharins, $\mathrm{N}$-halosulfonamides, $\mathrm{N}$-halosulfonimides in general, and $\mathrm{N}$ halosuccinimides ( $>\mathrm{N}-\mathrm{X}$, Where $\mathrm{X}=\mathrm{Cl}, \mathrm{Br}$, I etc.) in particular ${ }^{31-37}$. This is supported by the fact that $\mathrm{N}$ halocompounds are good sources of halonium cations $\left(\mathrm{X}^{+}\right)$, hypohalite species (HOX) and nitrogen anions. The electronegativities of chlorine, bromine, nitrogen and oxygen are 2.83, 2.74, 3.07 and 3.5 respectively, on Pauling's electronegativity scale ${ }^{38}$.

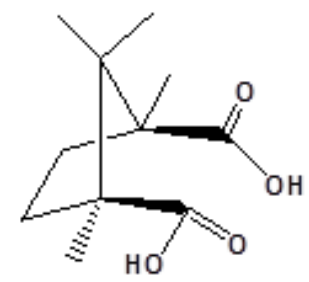

Camphoric Acid

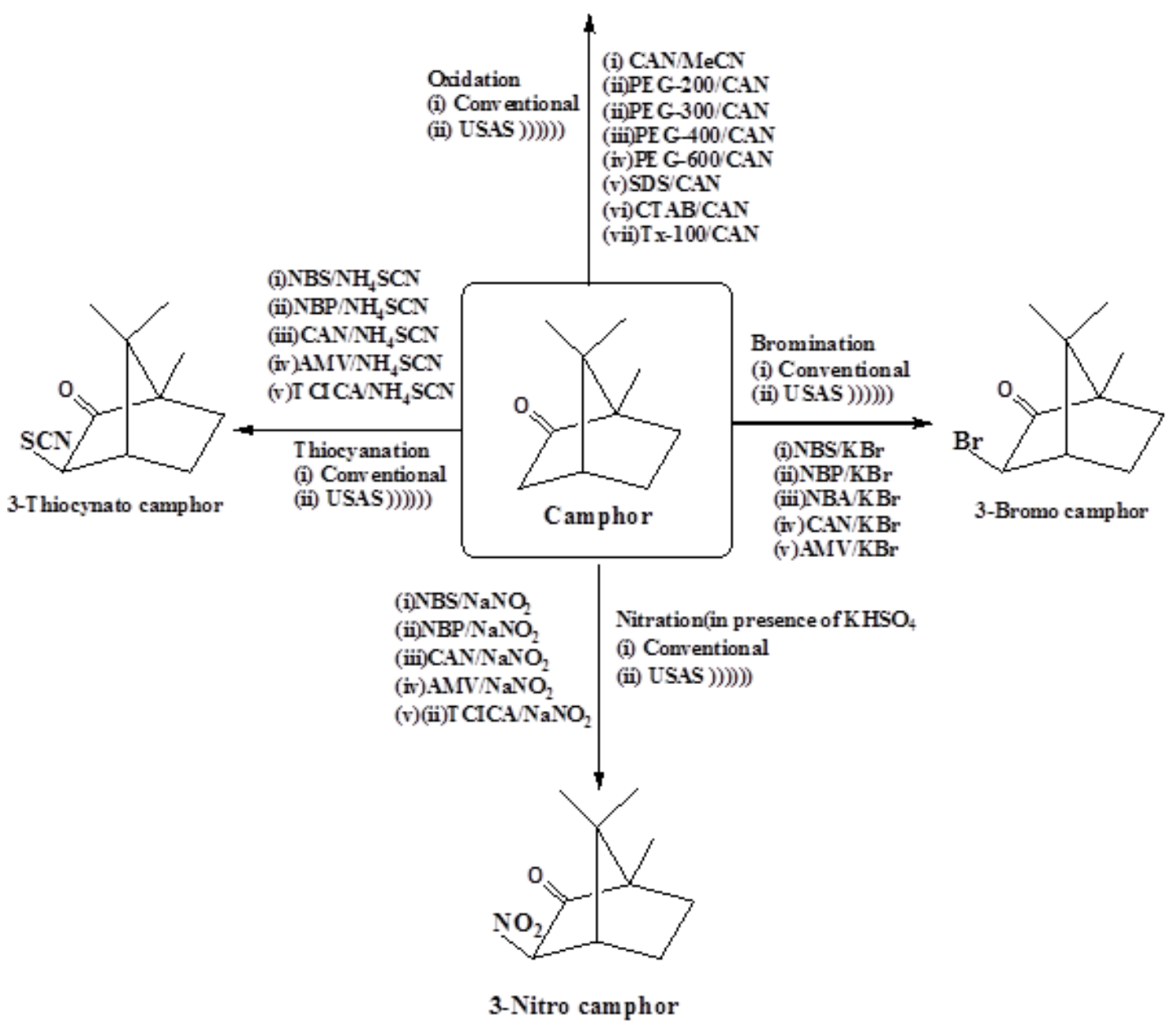

Scheme-1: Substitution and Oxidation reactions of Camphor

Thus the halogen acquires a positive oxidation state (except fluorine), when linked to oxygen or nitrogen. The electronegativity of nitrogen is further enhanced by linking it to certain electron withdrawing groups such as acyl groups. Thus, $N$-substituted haloimides are referred to as "positive halogen" compounds. The greater electronegativity of the nitrogen atom coupled with relatively more positive halogen makes $N$ substituted haloimide or $\mathrm{N}$-substituted haloamide consequently as the stronger oxidant. Interestingly, $\mathrm{N}$ - 
RASĀYAN J. Chem.

Vol. 10 | No. 1 | 206 -217 | January - March | 2017

halosuccinimides took fore front lead as efficient oxidizing and electrophilic halogenating reagents among the family of $\mathrm{N}$-halo compounds that are stable, easy to manipulate, and produce less toxic imides as a byproduct. More specifically N-bromo compounds, such as NBS, NBP and NBA are more stable in neutral, aqueous or slightly acidic medium ( $\mathrm{pH} \mathrm{4.5)}$ and can, therefore, be used for oxidation at relatively lower $\mathrm{pH}$.

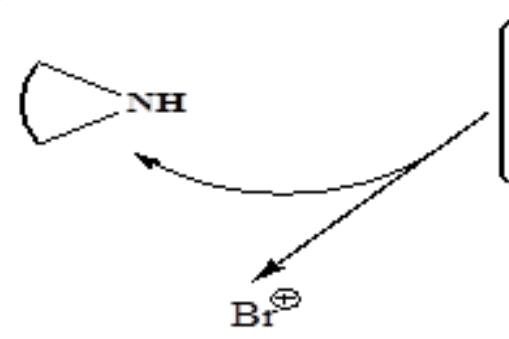

(Bromonium ion)

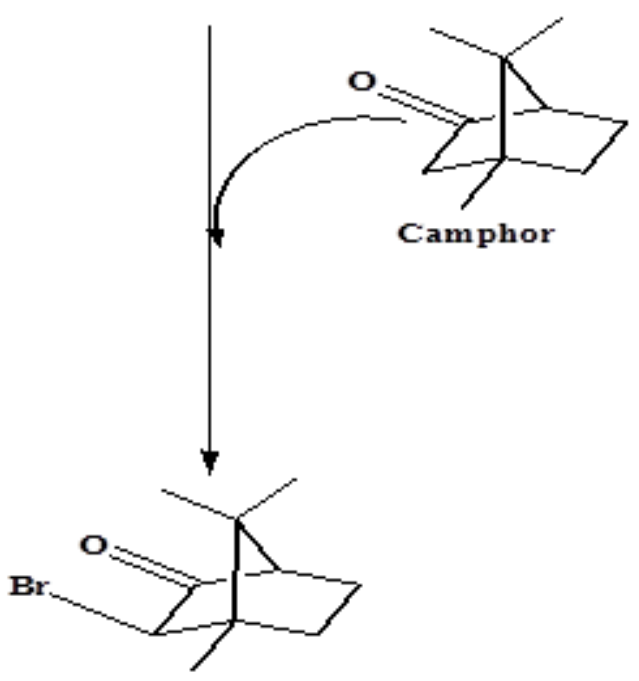

3-bromo camphor

Reaction occured with insitu gen erated $\mathrm{Br}^{+}$

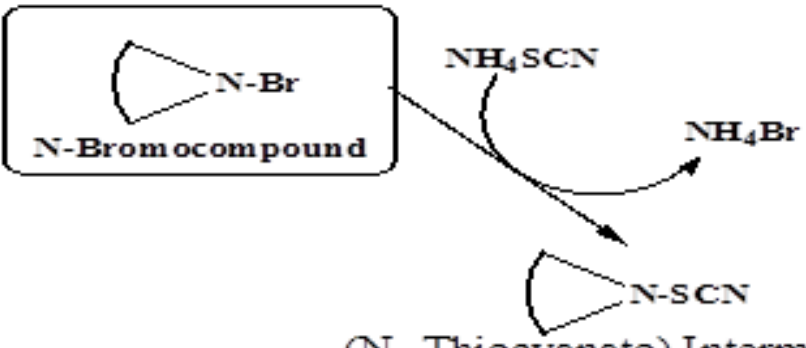

(N- Thiocyanato) Intermediate

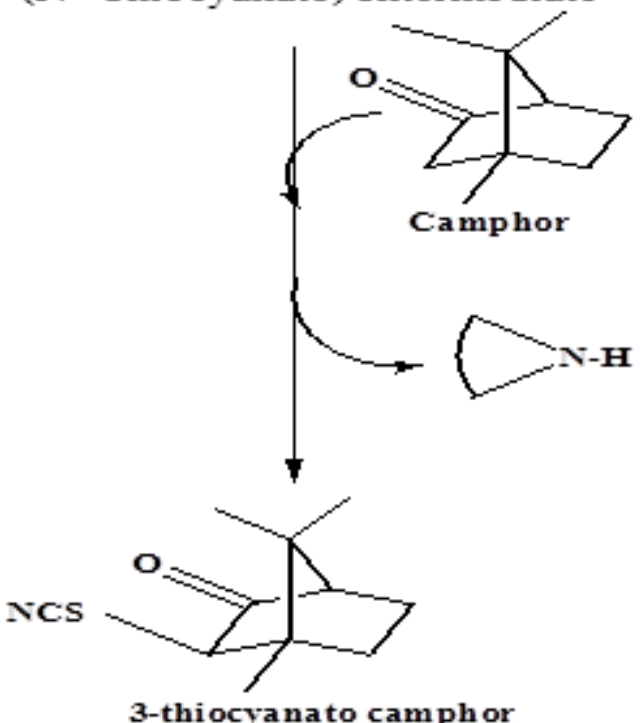

Reaction occured with insitu gen erated $\mathrm{SCN}^{+}$

Scheme-2A: Electrophilic Substitution of Camphor using N-Bromo reagents such as NBS, NBA, NBP

The oxidation potentials of the bromide-hypobromite couple are 0.76 and $1.33 \mathrm{~V}$ in neutral and alkaline media, respectively. NBS serves as a source of bromonium ion $\left(\mathrm{Br}^{+}\right)$or hypobromite of low concentration, and the reaction is free from the side reactions generally associated with the use of hypobromite solutions. In the oxidation reactions, NBS undergoes a simple two-electron reduction to give bromide ion and succinimide as products which do not interfere with the determination of organic compounds. There is abundant evidence that in polar media the oxidation reactions proceed via a "positive" halogen which is accepted to be the attacking species. ${ }^{26-28}$ On the basis of the foregoing elaborations on the reactive species of N-bromo compounds, bromination of camphor could be explained through the attack of $\mathrm{Br}^{+}$on the camphor afforded endo-3-bromo-D-camphor as ascertained from spectroscopic data. A perusal of the reaction times and corresponding product yield obtained from the reaction of camphor with $\mathrm{N}$-bromo compounds indicate that the reaction time for $\mathrm{NBS}<\mathrm{NBP}<=\mathrm{NBA}$, while the product yield followed a reverse trend: $\mathrm{NBA}>\mathrm{NBP}>\mathrm{NBS}$. This trend indicates higher selectivity of NBA over NBP and NBS, even though NBS releases $\mathrm{Br}^{+}$faster than NBP and NBA. Almost a similar trend is observed in sonicated reactions. It is also of interest to note that thiocyanation of camphor with 
NBP and NBS also followed a similar trend. The most plausible mechanism for electrophilic substitution of camphor with N-bromo reagents is shown in Scheme-2A and 2B. An insight into the reaction times and corresponding product yield obtained for the nitration of camphor with $\mathrm{N}$-bromo compounds in presence of $\mathrm{NaNO}_{2} / \mathrm{KHSO}_{4}$ indicate that the reaction time for NBS $<\mathrm{NBP}$, while the product yield followed a reverse trend: NBP>NBS. Nitration reaction is triggered by the formation of $\mathrm{HNO}_{2}$ due to the reaction between $\mathrm{KHSO}_{4}$ and $\mathrm{NaNO}_{2}$. The $\mathrm{HNO}_{2}$ thus formed, is oxidized by $\mathrm{N}-\mathrm{Bromo}$ compound to nitronium ion electrophile $\left(\mathrm{NO}_{2}^{+}\right)$, which in turn plausibly nitrates camphor to 3-nitrocamphor as shown in Scheme2B.

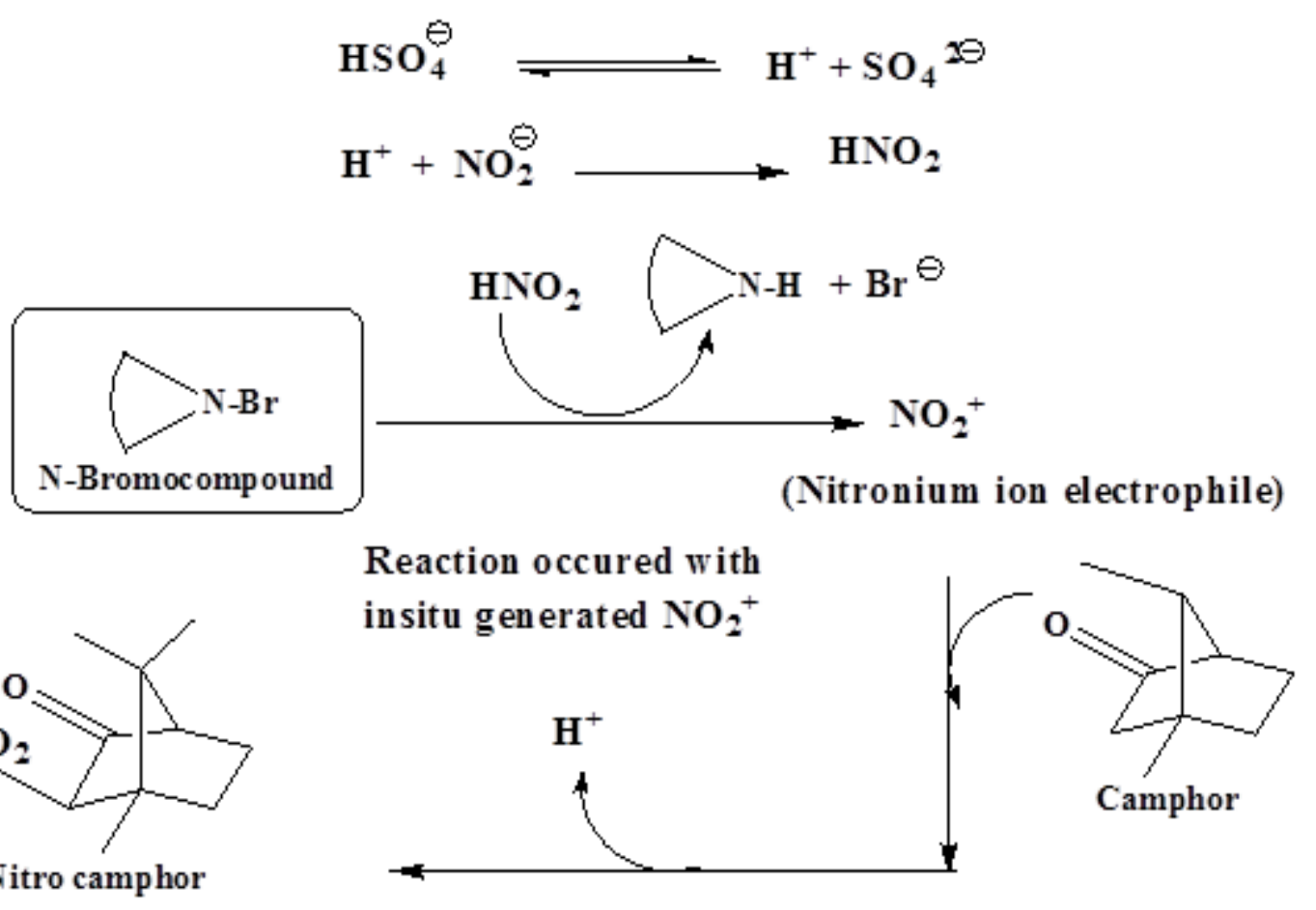

Scheme-2B: Electrophilic Nitration of Camphor using N-Bromo reagents such as NBS, NBA, NBP

On the other hand, few recent reviews demonstrated that trichloroisocyanuric acid (TCCA) and tribromoisocyanuric acid (TBCA) are efficient oxidants as well as halogenating agents, due to its capability of transferring a chlorine atom to unsaturated substrates in electrophilic reactions. ${ }^{39-42}$ Almeida et al also further revealed that the reactions with TCCA/KBr are faster than with TBCA, due to the in situ generated $\mathrm{Br}^{+}$, which is more electrophilic than the bromine atom in TBCA. ${ }^{43}$ Shanshan Liu and coworkers further explained that in TCCA/ ammonium thiocyanate mediated reactions, TCCA reacts initially with the added salt ( $\mathrm{KBr}$ for bromination, $\mathrm{NH}_{4} \mathrm{SCN}$ for thiocyanation) to generate electrophilic intermediate in situ $\left(\mathrm{Br}^{+}\right.$for bromination, $\mathrm{SCN}^{+}$for thiocyanation), which in turn reacts with camphor to give camphor derivative as shown in the following Scheme-3A.

However, the nitration reaction with TCCA in presence of $\mathrm{KHSO}_{4}$ and $\mathrm{NaNO}_{2}$ is initiated by the formation of $\mathrm{HNO}_{2}$ due to the interaction between $\mathrm{KHSO}_{4}$ and $\mathrm{NaNO}_{2}$. The $\mathrm{HNO}_{2}$ thus formed, is oxidized to nitronium ion electrophile $\left(\mathrm{NO}_{2}^{+}\right)$by TCCA, which in turn plausibly nitrates camphor to 3nitrocamphor as shown in Scheme-3B.

\section{Electrophilic bromination and thiocyanation of camphor with AMV and CAN]}

Electrophilic bromination of camphor using AMV and CAN as oxidation catalysts, the reactions are conducted under the conditions $[\mathrm{KBr}] \gg[\mathrm{AMV}]$ or $[\mathrm{CAN}]$, while thiocyanation reaction is conducted largely under similar conditions $\left(\left[\mathrm{NH}_{4} \mathrm{SCN}\right]>>[\mathrm{AMV}]\right.$ or $\left.[\mathrm{CAN}]\right)$. Electrophile $\left(\mathrm{E}^{+}\right)$is generated in situ 
by the oxidation of $\mathrm{Br}^{-}, \mathrm{SCN}^{-}$by $\mathrm{AMV}$ or $\mathrm{CAN}$. Electrophile thus generated $\left(\mathrm{Br}^{+}, \mathrm{SCN}^{+}\right)$attacks the electron-rich camphor at position-3 as shown in the following sequence of steps:

\section{Reaction mechanism with AMV catalyst}

Ammonium metavanadate (AMV) $/ \mathrm{KBr}$ initiated bromination of camphor could be explained by understanding the nature of various AMV species under experimental conditions in aqueous acetonitrile $(\mathrm{MeCN})$ medium. Ammonium metavanadate converts into $\mathrm{V}_{2} \mathrm{O}_{5}$ in solution and varieties of $\mathrm{V}(\mathrm{V})$ species were proposed to exist right from the findings of Littler and Waters ${ }^{44}$ depending on the nature of acid, solvent and other reaction conditions. ${ }^{45-47}$

$$
2 \mathrm{NH}_{4} \mathrm{VO}_{3} \longrightarrow \mathrm{V}_{2} \mathrm{O}_{5}+2 \mathrm{NH}_{3}+\mathrm{H}_{2} \mathrm{O}
$$

In presence of water $\mathrm{V}_{2} \mathrm{O}_{5}$ mainly converts into hydrated dioxovanadium $(\mathrm{V})$ ion $\left[\mathrm{VO}_{2}\left(\mathrm{H}_{2} \mathrm{O}\right)_{4}\right]^{+}$, which could be further be solvated with acetonitrile $(\mathrm{MeCN})$ according to the following equation,

$$
\left[\mathrm{VO}_{2}\left(\mathrm{H}_{2} \mathrm{O}\right)_{4}\right]^{+}+\mathrm{MeCN} \rightleftharpoons\left[\mathrm{VO}_{2}\left(\mathrm{H}_{2} \mathrm{O}\right)_{3}(\mathrm{MeCN})\right]^{+}+\mathrm{H}_{2} \mathrm{O}
$$

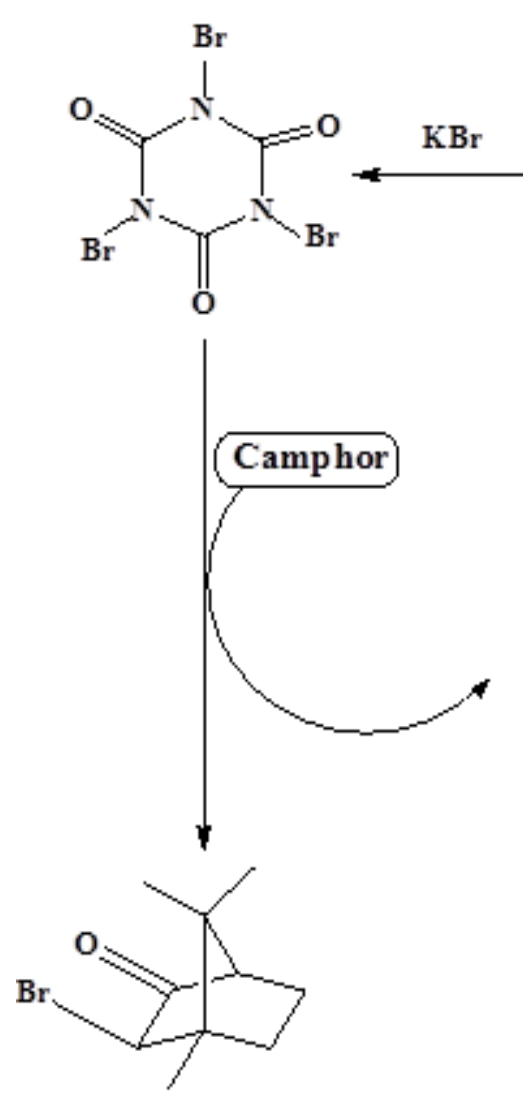

3-bromo camphor
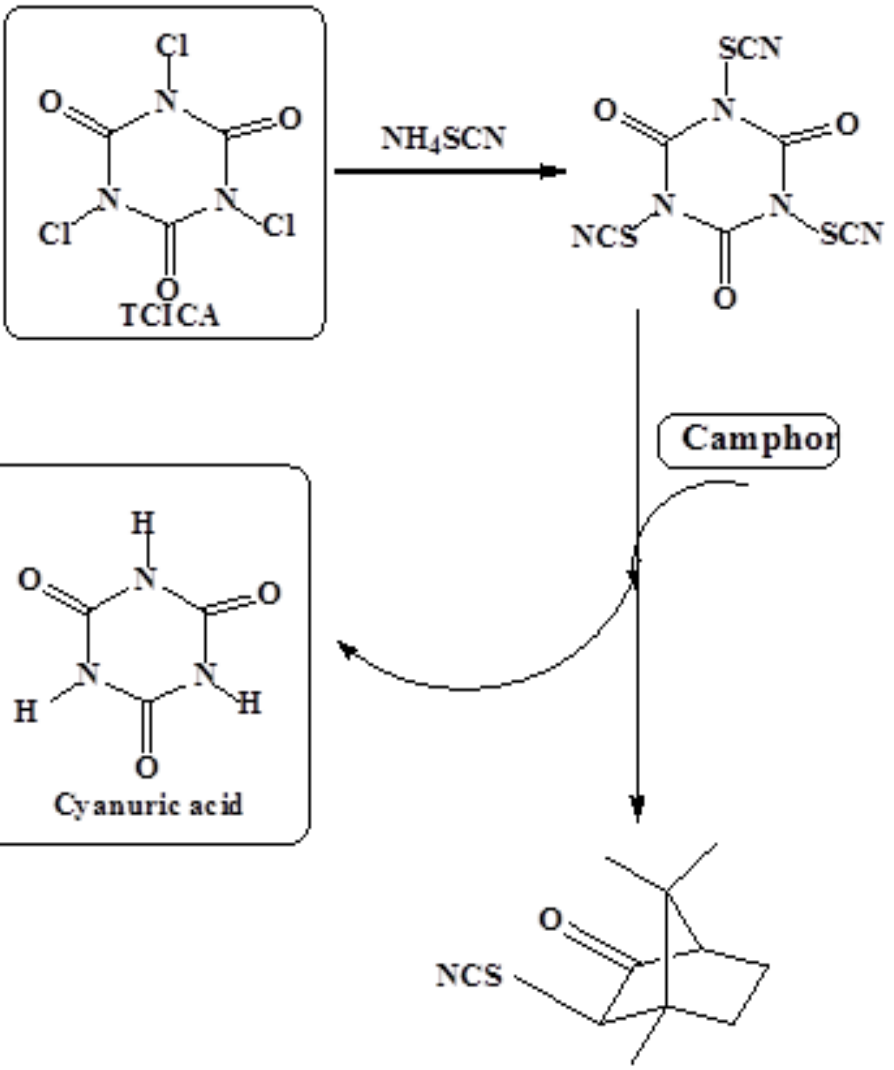

3-thiocyanato camphor

Scheme-3A: Electrophilic Bromination and thiocyanation reaction of Camphor with TCICA

Vanadium (V) thus formed oxidizes bromide $\left(\mathrm{Br}^{-}\right)$to give bromonium ion $\left(\mathrm{Br}^{+}\right)$species. Bromonium ion then attacks camphor to give 3-bromocamphor.

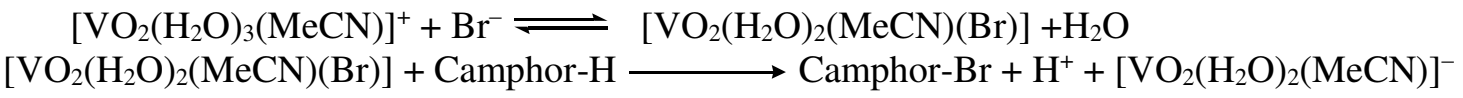


In the case of thiocyanation reaction the mechanism could be explained due to the generation of $\left[\mathrm{V}(\mathrm{OH})\left(\mathrm{H}_{2} \mathrm{O}\right)_{2}(\mathrm{MeCN})(\mathrm{SCN})\right]$ prior to the in situ generation of $\mathrm{SCN}^{+}$electrophile that finally converts camphor to give 3-camphor thiocyanate (3-thiocyanatocamphor).

However, in the case of nitration of camphor, AMV is used as a catalyst in presence of $\mathrm{NaHSO}_{4}$ and $\mathrm{NaNO}_{2}$ containing acetonitrile as co-solvent. Addition bisulfate generates acidic environment due to its in situ dissociation into $\mathrm{H}^{+}$and $\mathrm{SO}_{4}{ }^{2-}$, according to the following equilibrium,

$$
\mathrm{HSO}_{4}^{-}+\mathrm{H}_{2} \mathrm{O} \rightleftharpoons \mathrm{H}_{3} \mathrm{O}^{+}+\mathrm{SO}_{4}{ }^{2-}
$$

Therefore, it is more likely that hydrated dioxovanadium (V) ion $\left[\mathrm{VO}_{2}\left(\mathrm{H}_{2} \mathrm{O}\right)_{4}\right]^{+}$could be further be solvated with acetonitrile $(\mathrm{MeCN})$ according to the following equation,

$$
\begin{gathered}
{\left[\mathrm{VO}_{2}\left(\mathrm{H}_{2} \mathrm{O}\right)_{3}(\mathrm{MeCN})\right]^{+}+\mathrm{H}^{+}+\mathrm{HSO}_{4}^{-} \rightleftharpoons\left[\mathrm{VO}(\mathrm{OH})\left(\mathrm{H}_{2} \mathrm{O}\right)_{2}(\mathrm{MeCN})\left(\mathrm{HSO}_{4}\right)\right]^{+}+\mathrm{H}_{2} \mathrm{O}} \\
{\left[\mathrm{VO}_{2}\left(\mathrm{H}_{2} \mathrm{O}\right)_{3}(\mathrm{MeCN})\right]^{+}+\mathrm{H}^{+}+\mathrm{NO}_{2}^{-} \rightleftharpoons\left[\mathrm{VO}(\mathrm{OH})\left(\mathrm{H}_{2} \mathrm{O}\right)_{2}(\mathrm{MeCN})\left(\mathrm{NO}_{2}\right)\right]^{+}+\mathrm{H}_{2} \mathrm{O}}
\end{gathered}
$$

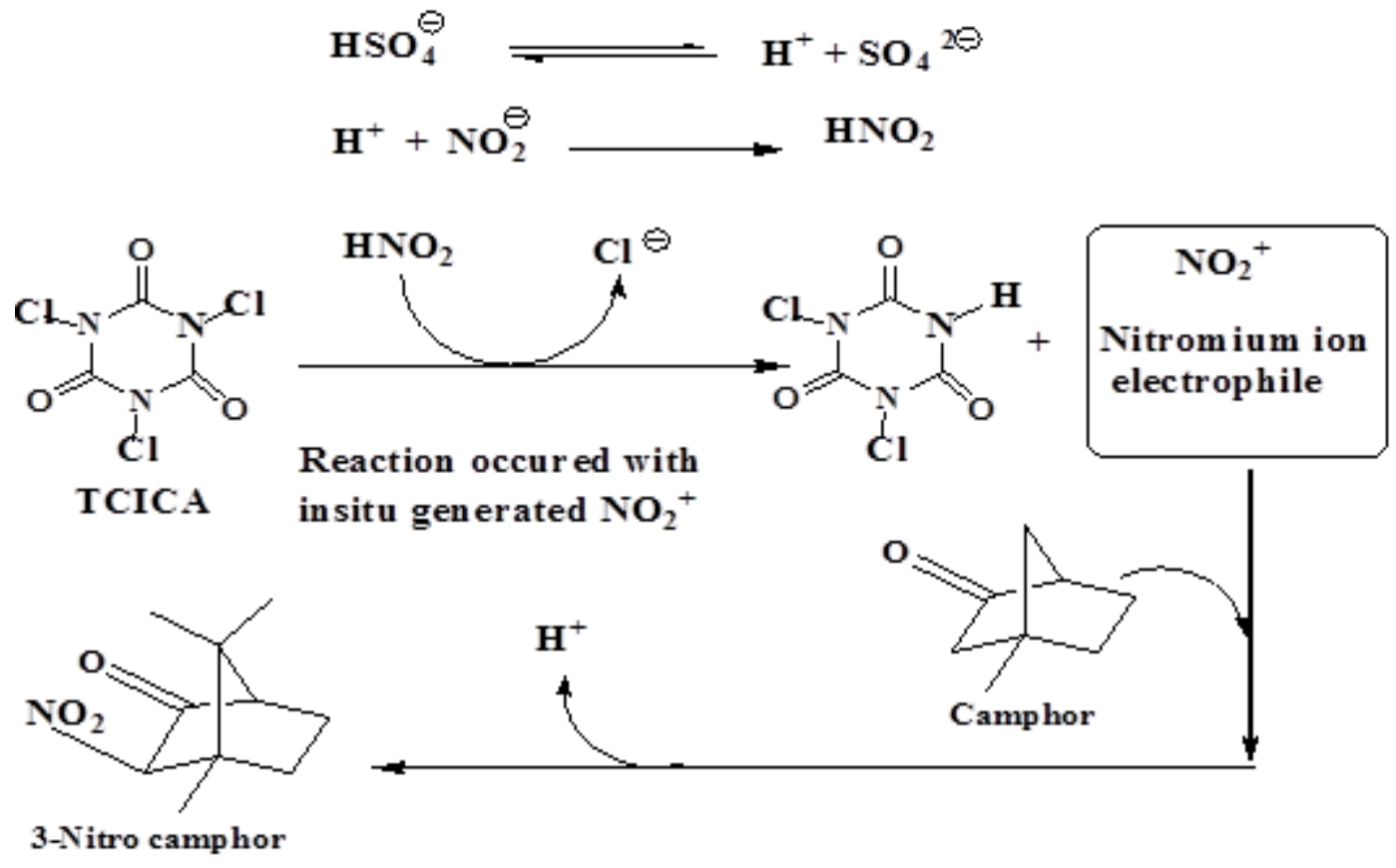

Scheme-3B: Electrophilic Nitration of Camphor using TCICA / $\mathrm{KHSO}_{4} / \mathrm{NaNO}_{2}$

Formation of nitrite bound $\mathrm{V}(\mathrm{V})$ species $\left[\mathrm{VO}(\mathrm{OH})\left(\mathrm{H}_{2} \mathrm{O}\right)_{2}(\mathrm{MeCN})\left(\mathrm{NO}_{2}\right)\right]^{+}$is more likely and more useful for nitration than $\left[\mathrm{VO}(\mathrm{OH})\left(\mathrm{H}_{2} \mathrm{O}\right)_{2}(\mathrm{MeCN})\left(\mathrm{HSO}_{4}\right)\right]^{+}$, since nitrite ion $\left(\mathrm{NO}_{2}^{-}\right)$is a harder base than bisulfate ion $\left(\mathrm{HSO}_{4}^{-}\right)$according to Pearson's $\mathrm{HSAB}$ theory. ${ }^{48}$ Formation of nitrite bound $\mathrm{V}(\mathrm{V})$ species $\left[\mathrm{V}(\mathrm{OH})\left(\mathrm{H}_{2} \mathrm{O}\right)_{2}(\mathrm{MeCN})\left(\mathrm{NO}_{2}\right)\right]^{+}$could be accomplished by the intensification of the yellow color of aquatic AMV. 3-Nitro camphor is formed due to the attack of in situ generated nitronium ion.

\section{Reaction mechanism with CAN catalyst}

Earlier reports on ceric ammonium nitrate (CAN) species such as $\mathrm{Ce}\left(\mathrm{NO}_{3}\right)_{6}{ }^{2-}, \mathrm{Ce}\left(\mathrm{NO}_{3}\right)_{5}{ }^{-}$, $\mathrm{Ce}(\mathrm{OH})\left(\mathrm{NO}_{3}\right)_{4}{ }^{-}, \mathrm{Ce}\left(\mathrm{NO}_{3}\right)_{4}$, and $\mathrm{Ce}(\mathrm{OH})^{3+}$ may exist in acid medium. ${ }^{49-52}$ However, CAN species in the $\mathrm{MeCN}$ medium could be entirely different. Since $\mathrm{MeCN}$ is large excess over [CAN], MeCN may 
RASĀYAN J. Chem.

Vol. 10 | No. 1 | 206 -217 | January - March | 2017

penetrate into the coordination spheres of Ce (IV) and form solvated CAN species according to the following equilibrium:

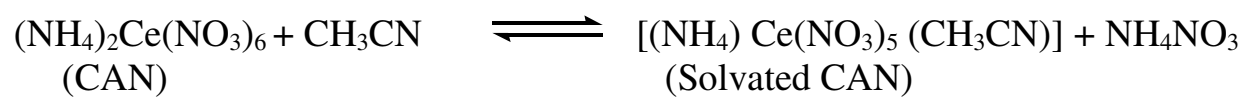

Solvated CAN may be able to oxidize bromide $\left(\mathrm{Br}^{-}\right)$to generate $\left(\mathrm{Br}^{+}\right)$, and thiocyanide $\left(\mathrm{SCN}^{-}\right)$to generate $\left(\mathrm{SCN}^{+}\right)$, which convert camphor to camphor derivatives according to the following reactions:

$$
\begin{aligned}
& {\left[\left(\mathrm{NH}_{4}\right) \mathrm{Ce}\left(\mathrm{NO}_{3}\right)_{5}\left(\mathrm{CH}_{3} \mathrm{CN}\right)\right]+\mathrm{Br}^{-} \rightleftharpoons} \\
& \left.\left[\mathrm{Ce}\left(\mathrm{NO}_{3}\right)_{4}(\mathrm{MeCN})(\mathrm{Br})\right]^{+}+\mathrm{Camphor}-\mathrm{H}\left(\mathrm{NO}_{3}\right)_{4}(\mathrm{MeCN})(\mathrm{Br})\right]^{+}+\left(\mathrm{NH}_{4}\right) \mathrm{NO}_{3} \\
& {\left[\left(\mathrm{NH}_{4}\right) \mathrm{Ce}\left(\mathrm{NO}_{3}\right)_{5}\left(\mathrm{CH}_{3} \mathrm{CN}\right)\right]+\mathrm{SCN}^{-} \rightleftharpoons \mathrm{Camphor}-\mathrm{Br}+\left[\mathrm{Ce}\left(\mathrm{NO}_{3}\right)_{4}(\mathrm{MeCN})\right]+\mathrm{H}^{+}} \\
& {\left[\mathrm{Ce}\left(\mathrm{NO}_{3}\right)_{4}(\mathrm{MeCN})(\mathrm{SCN})\right]^{+}+\mathrm{Camphor}-\mathrm{H} \longrightarrow\left[\mathrm{Ce}\left(\mathrm{NO}_{3}\right)_{4}(\mathrm{MeCN})(\mathrm{SCN})\right]^{+}+\left(\mathrm{NH}_{4}\right) \mathrm{NO}_{3}}
\end{aligned}
$$

However, in the case of nitration of camphor with CAN/Nitrite is conducted in presence of $\mathrm{KHSO}_{4}$ containing acetonitrile as co-solvent. Addition bisulfate generates acidic environment due to its in situ dissociation into $\mathrm{H}^{+}$and $\mathrm{SO}_{4}{ }^{2-}$, according to the dissociation equilibrium (6). Formation of nitrite bound $\mathrm{Ce}(\mathrm{IV})$ species could be shown as,

$$
\left[\left(\mathrm{NH}_{4}\right) \mathrm{Ce}\left(\mathrm{NO}_{3}\right)_{5}\left(\mathrm{CH}_{3} \mathrm{CN}\right)\right]+\mathrm{H}^{+}+\mathrm{NO}_{2}^{-} \rightleftharpoons \quad\left[\mathrm{HCe}\left(\mathrm{NO}_{3}\right)_{4}(\mathrm{MeCN})\left(\mathrm{NO}_{2}\right)\right]^{+}+\left(\mathrm{NH}_{4}\right) \mathrm{NO}_{3}
$$

Species thus formed oxidize nitrite $\left(\mathrm{NO}_{2}^{-}\right)$to generate nitronium ion $\left(\mathrm{NO}_{2}{ }^{+}\right)$in situ, which in turn nitrates camphor to camphor nitrate.

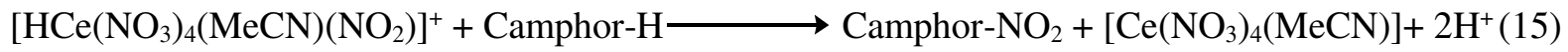

\section{CAN mediated Oxidation of Camphor in PEG and micellar media under acid-free conditions}

Oxidation reactions with camphor by CAN are considerably sluggish in aqueous acetonitrile media even at reflux temperatures with longer reaction times. The reactions afforded camphoric acid which is in accordance with earlier reports ${ }^{53}$. However, the reactions recorded magnificent rate accelerations in presence of micelle-forming surfactants (SDS, CTAB, Tx-100) and PEGs (PEG-200, PEG-300, PEG-400 and PEG-600), which could be seen from the data presented in Table-1. The rate enhancement in TX-100 micellar medium is on par with PEG. attributed This observation could be attributed probably because PEGs and TX-100 behave in the same way due to the presence of poly-oxy ethylene moieties in their structures. However, anionic (SDS) and cationic (CTAB) micelle mediated reactions depicted relatively less effect over TX-100 (Tables 1). Rate accelerations in micellar media could be attributed to the fact that micelles are known to act as micro to nano reactors. ${ }^{20}$

Another interesting feature in our studies is the accelerating effect of sonication on the rate of all substitution reactions observed in ultrasonically assisted reactions. The rate accelerations of the ultrasonically assisted could be due to cavitation phenomena ${ }^{40-43}$, a physical process that creates, enlarges, and implodes gaseous and vaporous cavities in an irradiated liquid. Cavitation is a process in which mechanical activation destroys the attractive forces of molecules in the liquid phase. When the sample is subjected to sonication, ultrasound waves propagate into the liquid media resulting in alternating highpressure (compression) and low-pressure (rare faction) cycles. During rarefaction, high-intensity sonic waves create small vacuum bubbles in the liquid, which then collapse violently during compression, creating very high local temperatures in the liquid and enhance mass transfer. The reaction times under conventional stirred conditions reduced from several hours to about only a few minutes in ultrasonically assisted condition. It is of interest to note that the results obtained in the present study are comparable 
RASĀYAN $J$. Chem.

Vol. 10 | No. 1 |206 -217 | January - March | 2017

with some of the earlier reports, which can be seen from the data presented in Table-1, indicating that the present work is also a sincere effort in the development of new eco-friendly protocols for substitution and oxidation reactions of camphor.

Table-1: Camphor Reactions

\begin{tabular}{|c|c|c|c|c|c|}
\hline \multirow[t]{2}{*}{ Reaction } & \multirow{2}{*}{$\begin{array}{l}\text { Reagent } \\
(0.1-0.15 \mathrm{~mol})\end{array}$} & \multicolumn{2}{|c|}{$\begin{array}{l}\text { Conventional } \\
\text { at } 320-330 \mathrm{~K}\end{array}$} & \multicolumn{2}{|c|}{$\begin{array}{l}\text { Sonication } \\
\text { at } 303 \mathrm{~K}\end{array}$} \\
\hline & & $\begin{array}{l}\text { Time } \\
\text { (hr) }\end{array}$ & $\begin{array}{l}\text { Yield } \\
(\%)\end{array}$ & $\begin{array}{l}\text { Time } \\
(\min )\end{array}$ & $\begin{array}{l}\text { Yield } \\
(\%)\end{array}$ \\
\hline \multirow[t]{5}{*}{ Bromination } & NBS & 4 & 70 & 55 & 75 \\
\hline & NBP & 5 & 73 & 50 & 73 \\
\hline & NBA & 5 & 80 & 45 & 79 \\
\hline & $\mathrm{CAN} / \mathrm{KBr}(0.2 \mathrm{~mol})$ & 6 & 77 & 55 & 81 \\
\hline & AMV/KBr(0.2 mol) & 5 & 81 & 50 & 80 \\
\hline \multirow[t]{5}{*}{ Thiocyanation } & $\mathrm{NBP} / \mathrm{SCN}(0.2 \mathrm{~mol})$ & 4 & 75 & 50 & 79 \\
\hline & $\mathrm{NBS} / \mathrm{SCN}(0.2 \mathrm{~mol})$ & 3 & 71 & 55 & 77 \\
\hline & AMV/SCN $(0.2 \mathrm{~mol})$ & 5 & 82 & 45 & 83 \\
\hline & TCICA/SCN $(0.2 \mathrm{~mol})$ & 6 & 86 & 40 & 72 \\
\hline & $\mathrm{CAN} / \mathrm{SCN}(0.2 \mathrm{~mol})$ & 6 & 84 & 45 & 78 \\
\hline \multirow{5}{*}{$\begin{array}{l}\text { Nitration } \\
\left(\mathrm{KHSO}_{4}\right) \\
(0.2 \mathrm{~mol})\end{array}$} & $\mathrm{AMV} / \mathrm{NaNO}_{2}(0.2 \mathrm{~mol})$ & 6 & 79 & 50 & 85 \\
\hline & TCICA/ $\mathrm{NaNO}_{2}(0.2 \mathrm{~mol})$ & 5 & 81 & 55 & 82 \\
\hline & $\mathrm{NBS} / \mathrm{NaNO}_{2}(0.2 \mathrm{~mol})$ & 3 & 74 & 35 & 75 \\
\hline & $\mathrm{NBP} / \mathrm{NaNO}_{2}(0.2 \mathrm{~mol})$ & 4 & 77 & 40 & 77 \\
\hline & $\mathrm{CAN} / \mathrm{NaNO}_{2}(0.2 \mathrm{~mol})$ & 6 & 88 & 55 & 83 \\
\hline \multirow{8}{*}{$\begin{array}{l}\text { Oxidation } \\
\text { (Acid-free) }\end{array}$} & CAN & 7.2 & 70 & 120 & 80 \\
\hline & CAN-SDS & 3.2 & 75 & 45 & 85 \\
\hline & CAN-CTAB & 4.0 & 80 & 65 & 85 \\
\hline & CAN-Tx-100 & 2.5 & 76 & 40 & 81 \\
\hline & CAN-PEG-200 & 2.8 & 72 & 26 & 86 \\
\hline & CAN-PEG-300 & 3.8 & 77 & 53 & 88 \\
\hline & CAN-PEG-400 & 4.6 & 73 & 62 & 85 \\
\hline & CAN-PEG-600 & 5.1 & 76 & 74 & 82 \\
\hline
\end{tabular}

\section{CONCLUSION}

In summary, we have developed a simple and efficient methods for substitution (bromination, thiocyanation, and nitration) reactions of camphor (CAMP) using an array oxidizing catalysts such as NBromosuccinimide (NBS), N-Bromophthalimide (NBP), N-Bromo acetamide (NBA), trichloroisocyanuric acid (TCICA), ceric ammonium nitrate (CAN), and ammonium metavanadate (AMV) in presence suitable salt as additive. Bromination is carried out with the reagent in presence of $\mathrm{KBr}$, while thiocyanation is done in presence of $\mathrm{NH}_{4} \mathrm{SCN}$ under acid-free conditions. However, nitration is carried out in presence of $\mathrm{NaNO}_{2}$ and $\mathrm{KHSO}_{4}$. Highly significant rate accelerations are recorded in ultrasonically assisted reactions, which were explained due to cavitation effects. On the other hand, the sluggish CAN oxidation of camphor underwent substantial rate acceleration in presence of PEGs and micelles. Present protocols have several advantages, such as simple work-up, fast reaction times, high product yield, eco-friendly and readily available additives as catalysts with experimental simplicity.

\section{REFERENCES}

1. (a) J.C. Mann, J.B. Hobbs, D.V. Banthorpe, J. B. Harborne. Natural products: their chemistry and biological significance. Harlow, Essex, England: Longman Scientific \& Technical, 309 (1994); (b) J. L. Simonsen and L. N. Owen, The Terpenes-The Dicyclic Terpenes and their derivatives(2nd Edition) New York: Cambridge University Press, 2, (1949). 
RASĀYAN J. Chem.

Vol. 10 | No. 1 | 206 -217 | January - March | 2017

2. (a) A. Pelter and S. H. Harper, In Rodd's Chemistry of Carbon Compounds, Amsterdam: Elsevier, IIc, 136 (1969); (b) R. T. Brown, In “Rodd's Chemistry of Carbon Compounds”, Amsterdam :Elsevier, IIc (Suppl),53(1974)

3. P. de Mayo, Mono- and Sesquiterpenoids, New York: Interscience, 11, 132(1959)

4. G. Samuelsson, Drugs of Natural Origin, Sweden: Swedish Pharmaceutical Press, 259(1999).

5. T. Money, Organic Synthesis: Theory and Application; Stamford, CT: JAI Press, 3,1(1996).

6. W.C. Evans, J. L. Simon Sen, M.J. Bhaghat, J. Chem. Soc. 444 ( 1934).

7. C. R. Eck, R.W. Mills, T. Money, J. Chem. Soc. Perkin I, 251(1975)

8. P. Cachia, N. Darby, C. R. Eck, T. Money, J. Chem. Soc. Perkin I, 359(1976).

9. J. Kannappan, A. V. Bedekar, J. Chem. Res., 36, 141, (2012)

10. P. Chandrasekhar, Conducting Polymers: Fundamentals and Applications, London: Kluwer Academic Publishers 16-21, 101-124(1999)

11. K. Chakrabarti, R. Chakrabarti, K.K. Chattopadhyay, S. Chaudhuri, A.K. Pal, Diamond and Related Materials. ,7, 845 (1998).

12. M. Kumar, Y. Ando "Carbon Nanotubes from Camphor: An Environment-Friendly Nanotechnology". J . Phys. Conf. Ser., 61, 643(2007)

13. P. Anastas, J. Warner, Green Chemistry: Theory and Practice, New York: Oxford University Press (1998).

14. (a) J.M. Harris, S. Zalipsky, Poly (ethylene glycol): Chemistry and Biological Applications, Washington, D.C. : ACS Books (1997); (b) T.J. Dickerson, N.N. Reed, K.D. Janda, Chem. Rev., 102, 3325 (2002); (c) J.M. Ahn, Jr. P. Wentworth, K.D. Janda, Chem. Commun., 480,(2003).

15. (a) T. Welton, Chem Rev., 99, 2071(1999); (b) M. Freemoutle, Chem. Eng. News, 78, 37 (2000).; Chem. Eng. News,79, 21(2001); (c) P. Wassercheid, W. Keim. Angew. Chem. Int. Ed., 39, 3772,(2000).

16. C. Ji, K.S. Scott, G.H. Jonathan, D.R. Robin. Green Chem., 7, 64(2005).

17. (a) J.H. Fendler, R.J. Fendler, Catalysis in Micellar and Micro-molecular Systems., New York: Academic Press (1975); (b) J. van Stam, S. Depaemelaere, F. D. Schryver, J. Chem. Educ., 75, 93 (1998); (c) J. H. Fendler, W.L. Hinze, J. Am. Chem. Soc., 103, 5439(1981)

18. (a) E. J. R. Sudhölter, G. B. van de Langkruis, J. B. F. N. Engberts, Recl. Trav. Chim. Pays-Bas, 99, 73 (1980).; (b) van Stam, J.; Depaemelaere, S.; D Schryver, F. J. Chem. Educ., 75, 93 (1998)

19. (a) K. C. Rajanna; M. M. Ali; S. Sana; Tasneem; P. K. Saiprakash;. Synthetic Com., 32, 1351(2002); (b) K.C. Rajanna, M. Satish Kumar, P. Venkanna, S. Ramgopal, M. Venkateswarlu, Inter. Natl. J. Org. Chem., 1, 250 (2011); (c) S. Sana, K.C. Rajanna, K. Rajendar Reddy, M. Bhooshan, M. Venkateswarlu, M. Satish Kumar, K. Uppalaiah,Green Sustain. Chem, 2, 97(2012).;(d) M.M. Ali, Tasneem, K. C. Rajanna, P.K. Saiprakash, Synlett, 251 ( 2001); (b) K. C. Rajanna, M.M. Ali, S. Sana, Tasneem, P.K. Saiprakash, J. Disp. Sci. Tech. 25, 17(2004)

20. E. H. Wanderlind, E. S. Orth, M. Medeiros, D. M. P. O. Santos, E. Westphal, H.Gallardo, H. D. Fiedler, F. Nome, J. Braz. Chem. Soc., 25, 2385, (2014)

21. (a) T.J. Mason, Chemistry with Ultrasound, New York: Elsevier Applied Science (1990); (b) T.J. Mason and J. Lindley, Chem. Soc. Rev., 16, 239(1987); (c) M.J. Blandamer, Introduction to Chemical Ultrasonics, New York: Academic Press (1973).

22. (a) R. Taylor, Electrophilic Aromatic Substitution. Chi Chester: Wiley, 1990); (b) R. M. Roberts and A. A. Khalaf, Friedel-Crafts Alkylation, New York: Marcel Dekker (1984); (c) G. A. Olah, FriedelCrafts Chemistry, New York: Wiley-Interscience (1973).

23. (a) G. A. Olah, R. Malhotra and S. C. Narang, Nitration Methods and Mechanisms, New York: VCH, (1989); (b) P. B. De La Mare, Electrophilic Halogenation; Cambridge: Cambridge University Press, (1976); (c) S. Duan; J. Turk; J. Speigle; J. Corbin ; R. J. Baker., J. Org. Chem., 65, 3005(2000).

24. (a.) J.L. Wood, Organic Reactions., New York: Wiley, 3, 240 (1967); (b.) T.R. Kelly, M.H. Kim, A.D.M. Certis.Org. Chem., 58, 5855 (1993).; (b) R. G. Guy, In: S. Patai (Ed.), The Chemistry of Cyanates and their thioderivatives., New York: John Wiley\& Sons (1977); (c) J.S. Yadav, B. V. S. Reddy, S. Shubashree, K. Sadashiv, Tetrahedron Lett., 45, 2951(2004). 
RASĀYAN $J$. Chem.

Vol. 10 | No. 1 |206-217 | January - March | 2017

25. H. Veisi, R. Ghorbani-Vaghei, M. A. Zolfigol, Organic Prep. Proc.Int., 43, 489(2011)

26. (a) S. P. L. De Souza, J. F. M. Da Silva, M.C.S. De Mattos, Synth. Commun., 33, 935(2003); (b) S. P. L. De Souza, J. F. M. Da Silva, M.C.S. De Mattos, J. Braz. Chem. Soc., 14, 832(2003).

27. A.V. Joshi, M. Baidossi, S. Mukhopadhyay, Y. Sasson, Org. Process Res. Dev., 8, 568(2004).

28. N. K. Mathur, C. N. Narang, Determination of organic compounds with N-Bromosuccinimide and allied reagents (Analysis of Organic Materials), London: Academic Press, 8,(1975).

29. (a)M.A. Goodman, M.R. Detty, Organometallics, 23, 3016(2004);;(b) J. H. Espenson, Z. Zhu, T. H. Zauche., J. Org. Chem., 64, 1191 (1999)

30. V. Kavala, S. Naik, B.K. Patel, J. Org. Chem., 70, 4267,(2005).

31. P.V.Vyas, A.K. Bhatt, G. Ramachandraiah, A.V. Bedekar, Tetrahedron Lett., 44, 4085(2003).

32. (a) L.M. Matthew, R. M. Yogesh, M.Steven, Tetrahedron Lett, 46, 4749 (2005); (b) H. Normant, Adv Org Chem, 2, 165,( 1960).;(c) M.C. Carreno, J. L. Garcia Ruano, G. Sanz, M.A. Toledo, A.N. Urbano, J Org Chem., 60, 5328(1995)

33. (a) F.L. Lambert, W.D. Ellis, R.J. Parry, J Org Chem., 30, 304(1965); (b) K. Tanemura, T.Suzuki, Y. Nishida, K. Satsumabayashi, T. Horaguchiy, Chem Lett., 32, 932 (2003)

34. (a) S. Gunasekaran, N. Venkatasubramanian, Proc Indian Acad Sci., 92, 107(1983); (b) D.V. Prabhu, J. Ind. Chem Soc., 84, 1135 (2007).

35. R.V. Jagdeesh, Puttaswamy, J. Phy Org Chem, 21, 844 ( 2008)

36. A.K. Singh, B. Jain, R. Negi, Y. Katre, S.P. Singh, V.K. Sharma, Trans Met Chem.,4, 521(2009)

37. B. Anjaiah, M. Satish Kumar, P. Srinivas, K. C. Rajanna, Int. Natl J. Chem. Kinet, 48, 98( 2016)

38. R.C. West; CRC Handbook of Chemistry and Physics; Boca Raton: Press, (1977)

39. (a) U. Tilstam, H. Weinmann, Org. Process Res. Dev., 6, 384 ( 2002).; (b) M. Zolfigol, E. Madrakian, E. Ghaemi, S. Mallakpour, Synlett.,1633(2002)

40. (a) G.F. Mendonça, R.M. Magalhães, M.C.S. De Mattos, P. M. Esteves, P. M. J. Braz. Chem. Soc. 16, 695(2005);(b) M. Wengert, A. M. Sanseverino, M.C.S. De Mattos, J. Braz. Chem. Soc., 13, $700,(2002)$

41. G.F. Mendonça, A. M. Sanseverino, M.C.S. De Mattos, Synthesis., 45(2003).

42. (a) L.S. de Almeida, P.M. Esteves, M.C. de Mattos, Synthesis, 221, (2006);(b)L. S.de Almeida, P.M. Esteves, M.C. S. de Mattos., Synlett., 1515 (2006)

43. S. Liu, Z. Guo, Y. Yang, T. Wang, L. Wu, Bull. Korean Chem. Soc., 32, 3760, (2011)

44. W.A. Waters, J.S. Litter, J. Chem. Soc. 3014, (1959)

45. (a) A. Kumar and R. N. Mehrotra, Int. J. Chem. Kinet., 6,15 (1974); (b) R. N. Mehrotra, J. Chem. Soc. B, 642 (1968);(c) D. M. West and D. A. Skoog, J. Am. Chem. Soc., 82,280 (1960); (d) R. N. Mehrotra, Ind. J. Chem., 12,365 (1974); (e) S. Narasimhan, N. Venkatasubramanian, Int. J. Chem. Kinet., 11, 883(1979)

46. (a) V.I.E. Bruyere, L.A.G. Rodenas, P.J. Morando, M.A. Blesa, J. Chem. Soc. Dalton Trans. 3593(2001); (b) P.C. Wilkins, M.D. Johnson, A.A. Holder, D.C. Crans, Inorg. Chem. 45, 1471 (2006); (c) R. Shankar, S.N. Joshi, Indian J. Chem. 1, 289 (1963)

47. (a) B. Saha, S. Sarkar, K. M. Chowdhury, Int. J. Chem. Kinet.,40,280 (2008); (b)S. Saccubai, M. Santappa, Indian J. Chem. 8, 533 (1970); (c) Z. Khan, P.S.S. Babu, Kabir-ud-Din, Carbohydrate. Res. 339, 133, (2004); (d) A. Kumar, R. N. Mehrotra. J. Org. Chem., 40, 1248 (1975)

48. F. Basolo, R.G. Pearson, Mechanisms of inorganic Reactions-A Study of Metal Complexes in Solution. 2nd ed. John Wiley \& Sons, Inc., New York, June, (1967).

49. K. V. Rao and S. S. Muhammed, Bull. Chem. Soc. Japan, 36, 943 (1963).

50. S. S. Muhammed and B. Sethuram, Acta Chim.Hungy, 46, 115(1965).

51. N. Dutt, R. R. Nagori, and R. N. Mehrotra, Can. J. Chem, 64, 19 (1986).

52. K. Ramesh, S. Shylaja, K. C. Rajanna, P. Giridhar Reddy, and P. K. Saiprakash., Adv.Phys. Chem., 2013 (2013), Article ID 146585. Advances in Phys. Chem., 2013 (2013), Article ID 835610 and references cited therein.

[RJC-1608/2017] 